\title{
Specific Lipid and Metabolic Profiles of R-CHOP-Resistant Diffuse Large B-Cell Lymphoma Elucidated by Matrix-Assisted Laser Desorption lonization Mass Spectrometry Imaging and in Vivo Imaging
}

Florian P.Y. Barré, ${ }^{\dagger, \#}$ Britt S.R. Claes, ${ }^{\dagger, \#}$ Frédéric Dewez, ${ }^{\dagger}$ Carine Peutz-Kootstra, ${ }^{\ddagger}$ Helga F. Munch-Petersen, ${ }^{\S}$ Kirsten Grønbæk, ${ }^{\|, \perp}$ Anders H. Lund, ${ }^{\perp}$ Ron M.A. Heeren, ${ }^{\dagger}$ Christophe Côme, ${ }^{\|, \perp, \mathbb{I}}$ and Berta Cillero-Pastor*, ${ }^{\dagger}, I_{[\odot}$

${ }^{\dagger}$ The Maastricht Multimodal Molecular Imaging Institute (M4I), Division of Imaging Mass Spectrometry, Maastricht University, 6229 ER Maastricht, The Netherlands

${ }^{\ddagger}$ Department of Pathology, Maastricht University Medical Center, Cardiovascular Research Institute Maastricht, 6229 HX Maastricht, The Netherlands

${ }^{\S}$ Department of Haematology and Department of Pathology, Rigshospitalet, 2100 Copenhagen, Denmark

"Epigenomlaboratoriet, Rigshospitalet Dept. 3733, Bartholin Institute, Copenhagen Biocenter, 2200 Copenhagen, Denmark

${ }^{\perp}$ Biotech Research and Innovation Centre (BRIC), University of Copenhagen, 2200 Copenhagen, Denmark

\section{Supporting Information}

ABSTRACT: Diffuse large B-cell lymphoma (DLBCL) is the most common B-cell non-Hodgkin lymphoma. To treat this aggressive disease, R-CHOP, a combination of immunotherapy ( $\mathrm{R}$; rituximab) and chemotherapy (CHOP; cyclophosphamide, doxorubicin, vincristine, and prednisone), remains the most commonly used regimen for newly diagnosed DLBCLs. However, up to one-third of patients ultimately becomes refractory to initial therapy or relapses after treatment, and the high mortality rate highlights the urgent need for novel therapeutic approaches based upon selective molecular targets. In order to understand the molecular mechanisms underlying relapsed DLBCL, we studied differences in the lipid and metabolic composition of nontreated

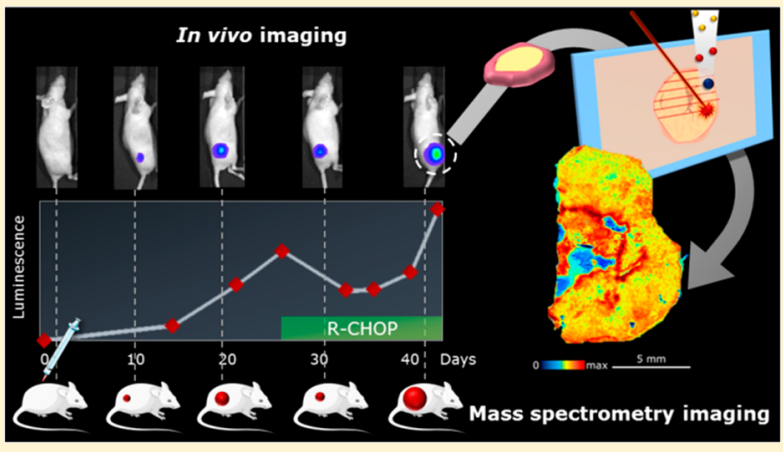
and R-CHOP-resistant tumors, using a combination of in vivo DLBCL xenograft models and mass spectrometry imaging. Together, these techniques provide information regarding analyte composition and molecular distributions of therapy-resistant and sensitive areas. We found specific lipid and metabolic profiles for R-CHOP-resistant tumors, such as a higher presence of phosphatidylinositol and sphingomyelin fragments. In addition, we investigated intratumor heterogeneity and identified specific lipid markers of viable and necrotic areas. Furthermore, we could monitor metabolic changes and found reduced adenosine triphosphate and increased adenosine monophosphate in the RCHOP-resistant tumors. This work highlights the power of combining in vivo imaging and MSI to track molecular signatures in DLBCL, which has potential application for other diseases.

$\mathrm{D}$ iffuse large B-cell lymphoma (DLBCL) is the most common B-cell non-Hodgkin's lymphoma (NHL) throughout the world, comprising $30-35 \%$ of all NHLs, with approximately 72580 new cases and 20150 deaths estimated for 2016. ${ }^{1}$ Implemented 20 years ago, R-CHOP, a combination of immunotherapy ( $R$ : rituximab, targeting the cell surface protein $\mathrm{CD} 20$ expressed by B-cell lymphoma) and chemotherapy (CHOP: cyclophosphamide, doxorubicin, vincristine, and prednisone), remains the most commonly used regimen for newly diagnosed advanced DLBCLs. This therapy has considerably improved treatment response, ${ }^{2-5}$ but DLBCL is a biologically aggressive disease and up to one-third of patients becomes refractory to initial therapy ${ }^{6}$ and displays a poor survival outcome. ${ }^{7,8}$

The high mortality rate in patients with relapsed DLBCL highlights the urgent need for novel therapeutic approaches based upon selective molecular targets. Therefore, it is of high importance to enhance our understanding of the various mechanisms leading to tumor resistance/relapse in order to develop efficient therapies against refractory/relapsing

Received: June 27, 2018

Accepted: November 13, 2018

Published: November 13, 2018 
DLBCL. To do so, two criteria are critical, (i) to precisely monitor DLBCL cells' response to R-CHOP treatment and tumor progression, and (ii) to analyze global and local molecular tumor profiles in relation to treatment response.

Implemented for the first time two decades ago, live in vivo bioluminescent imaging (BLI) has allowed researchers to detect living cells in rodents in a noninvasive manner. ${ }^{9}$ Cells are genetically modified in order to express a luciferase enzyme, which, after injection of luciferin in the animal, will lead to the emission of a luminescent signal. This signal is then acquired and quantified by an in vivo imaging system (IVIS). Of note, in cancer xenograft models, it also allows precise monitoring and quantification of tumor development from earlier stages and more accurately than caliper measurements. ${ }^{10}$ Moreover, in the past decade, scientists have generated lentiviral vectors coupling fluorescent markers and luciferase, allowing for the stable generation of luminescent variants of almost any cancer cell line. ${ }^{11}$ Such models have been previously shown to efficiently monitor lymphoma cells reaction to treatment in murine models. ${ }^{12}$

Mass spectrometry imaging (MSI) is an analytical tool capable of identifying and mapping hundreds of molecules in a single experiment from thin, biological sections. MSI differs from other imaging techniques as it is a label-free method used to study molecules ranging from proteins and peptides ${ }^{13}$ to lipids, ${ }^{14}$ metabolites, ${ }^{15}$ and drugs. ${ }^{16}$ MSI is commonly used to study and characterize different types of cancer. ${ }^{17,18}$

Matrix-assisted laser desorption/ionization (MALDI) is one of the main ionization techniques used in the MSI field. A thin layer of matrix is deposited on-top of the sample in order to help ionization and desorption of the molecules. Then, a laser shoots across the tissue section recording the biomolecular profile (mass-to-charge ratio and relative intensity) of each acquired position. Dedicated software allows the generation of images at a given pair of $x$ - and $y$-coordinates. MALDI-MSI ${ }^{19}$ offers a very high spatial resolution (up to $1-5 \mu \mathrm{m})^{20,21}$ and an acquisition speed of 50 pixels per second, ${ }^{22}$ providing histological information at the biomolecular level.

Recent studies have demonstrated the advantages of combining in vivo imaging and MSI in cancer research. Indeed, Hinsenkamp et al. demonstrated the potential of the ROCK1/2 inhibitor Fasudil in a gastric cancer model either by positron emission tomography-computed tomography (PET/ $\mathrm{CT}$ ) in vivo imaging or MALDI-MS imaging. ${ }^{23}$ Jiang et al. have identified specific lipid profiles of hypoxic regions in a breast cancer model by combining bioluminescence in vivo imaging and MSI. ${ }^{24}$ In this work, we demonstrate the potential of using BLI to follow the response to R-CHOP treatment and MALDI-MSI to characterize the molecular profiles of resistant tumors.

Our results reveal distinctive signatures of lipids and metabolites in R-CHOP-resistant lymphoma tumors that could help to identify new targets involved in treatment resistance. Furthermore, our studies demonstrate that BLIMALDI-MSI combined can be applied to study molecular and metabolic progression of many other diseases.

\section{EXPERIMENTAL SECTION}

The U2932 DLBCL cell line was obtained from American Type Culture Collection, USA. A luminescent and fluorescent variant of the cell line was generated, on the basis of the pFULT lentiviral system, as previously published (details in the Supporting Information). ${ }^{24,25}$
Generation of DLBCL Xenografts. The $10^{7}$ freshly harvested U2932 pFULT cells $(200 \mu \mathrm{L}$ from a stock solution of $5 \times 10^{7}$ cells $/ \mathrm{mL}$ in PBS) were subcutaneously injected in the right flank of 40 NMRI-nude adult females (Janvier Laboratories, France). Following injection, in vivo luminescence imaging was used to follow tumor development using an IVIS Lumina II (Caliper Life Sciences, USA). Mice were checked daily to detect any sign of discomfort or sickness and sacrificed by cervical dislocation if such condition would appear. Of the 40 injected mice, 33 developed tumors and did not present any side-effects. Of these 33 tumorous mice, 5 were left untreated as controls, and 28 were treated with an RCHOP regiment once the tumor had reached a total luminescence signal of at least $3 \times 10^{10}$ photons/second. One cycle of R-CHOP therapy was defined as three consecutive repeats of a weekly procedure, from indicated time-points, based on published protocols. ${ }^{26,27}$ One procedure consists of a single Rituximab (MabThera subcutaneous, Roche, Switzerland) subcutaneous injection on day 1, dosed at $25 \mathrm{mg} / \mathrm{kg}$ combined with CHOP treatment as follows: cyclophosphamide (Sigma-Aldrich, C0768, USA) intraperitoneal (i.p.), day 2, dosed at $40 \mathrm{mg} / \mathrm{kg}$; doxorubicin (SigmaAldrich, D2975000, USA), i.p., day 2, dosed at $3.33 \mathrm{mg} / \mathrm{kg}$; vincristine (Sigma-Aldrich, V0400000, USA) i.p., day 2, dosed at $0.2 \mathrm{mg} / \mathrm{kg}$; and prednisone (Sigma-Aldrich, P6254, USA), oral gavage from day 1 to 5 inclusive, dosed at $0.2 \mathrm{mg} / \mathrm{kg}$. The tumors were harvested and immediately heat-stabilized (Stabilizor System, Denator, Sweden) in order to preserve their molecular integrity before being snap-frozen in isopentane and then stored at $-80{ }^{\circ} \mathrm{C}$ until MSI analysis.

Mass Spectrometry Imaging. The $12 \mu \mathrm{m}$ consecutive sections were used in order to obtain technical triplicates of each tumor and type of MSI experiment (lipids positive mode, lipids negative mode, and metabolites).

Lipid Analysis. Prior to matrix application, the samples were dried for $15 \mathrm{~min}$. Norharmane (Sigma-Aldrich, Gillingham, UK) matrix was applied to sections at $7 \mathrm{mg} / \mathrm{mL}$ in 2:1 chloroform:methanol (v/v) using the TM-Sprayer M3 (HTX Technologies LLC, Carrboro, USA). Eleven layers were applied with a drying time of $30 \mathrm{~s}$ between each layer using a nozzle temperature of $30^{\circ} \mathrm{C}$ with a flow rate of $120 \mu \mathrm{L} / \mathrm{min}$. The velocity was set at $1200 \mathrm{~mm} / \mathrm{min}$ combined with a track passing of $3 \mathrm{~mm}$ allowing homogeneous matrix application. ${ }^{28}$

Metabolite Analysis. N-(1-Naphthyl) ethylenediamine dihydrochloride (NEDC) (Sigma-Aldrich, Gillingham, UK) matrix was applied to sections at $7 \mathrm{mg} / \mathrm{mL}$ in $70 \%$ methanol $(\mathrm{v} / \mathrm{v})$. The spray parameters were the same as for the lipids with the only difference that the nozzle temperature was set to $85{ }^{\circ} \mathrm{C}$. 9-Aminoacridine hydrochloride monohydrate (9AA) (Sigma-Aldrich, Gillingham UK) matrix was applied at $7 \mathrm{mg} /$ $\mathrm{mL}$ in $70 \%$ ethanol (v/v) using the SunCollect (SunChrom, Friedrichsdorf, Germany). Twenty layers were applied with a flow rate of $40 \mu \mathrm{L} / \mathrm{min}$ and a $\mathrm{Z}$ offset of $25 \mathrm{~mm}$. The velocity was set at $1250 \mathrm{~mm} / \mathrm{min}$ combined with a line distance of 2 $\mathrm{mm}$.

Lipids were detected using both positive and negative ion polarities and metabolites only in the negative mode using a Bruker RapifleX MALDI Tissue-typer instrument operating in reflectron mode (Bruker Daltonik GmbH, Germany) and an Orbitrap Elite hybrid ion trap mass spectrometer (Thermo Fisher Scientific, Bremen, Germany) (see the Supporting Information). 
A.
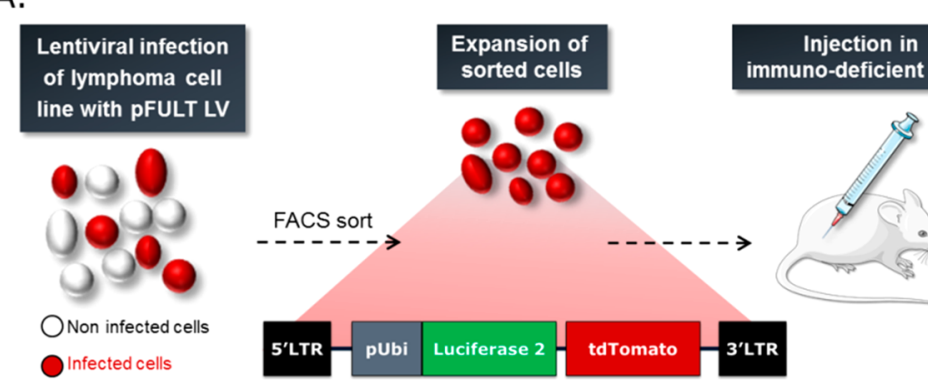

Injection in
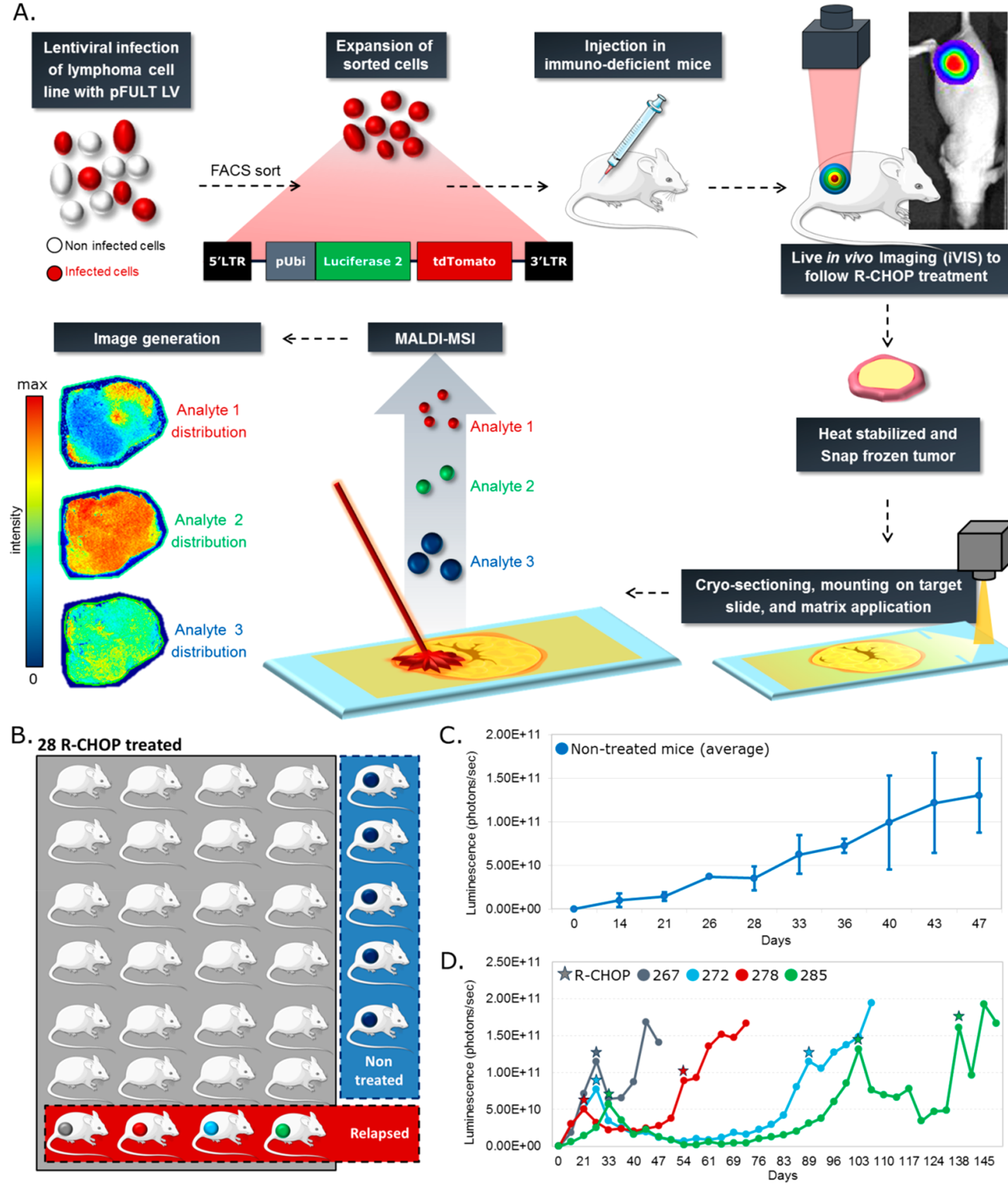

Figure 1. In vivo R-CHOP resistance of DLBCL cells monitored by in vivo imaging and classified by MSI. (A) Schematic of the experimental design and workflow. (B) Overview of the mice used for this study. (C) Averaged tumoral development of the 5 untreated mice. Points and bars are, respectively, mean \pm SD at indicated time-points. (D) Tumoral development of R-CHOP-resistant mice. Stars indicate initiation of a R-CHOP regimen, lasting 3 weeks. Final point for each mouse indicates tumor not responding to R-CHOP therapy anymore.

Imaging Processing. FlexImaging v4.1 (Bruker Daltonik $\mathrm{GmbH}$, Bremen, Germany) and SCiLS lab 2016b (SCiLS $\mathrm{GmbH}$, Bremen, Germany) were used to process the imaging data acquired with the Bruker RapifleX. Thermo Xcalibur 3.0.63 (Thermo Fisher Scientific, Bremen, Germany) was used to analyze the Orbitrap imaging data. Principal component analysis (PCA), hierarchical clustering analysis (HCA), and linear discriminant analysis (LDA) were performed after peak picking using an in-house-built ChemomeTricks toolbox for MATLAB version 2014a (The MathWorks, Natick, USA). ${ }^{29}$

On-tissue pixels were selected as regions of interest (ROIs) and assigned to a category representing the untreated and resistant classes, respectively. PCA-LDA was performed with one-fourth of the number of features as the number of functions for the LDA, ${ }^{30}$ which were 337 functions for lipids in negative polarity, 338 functions for lipids in positive polarity, and 357 functions for metabolites. The scores that described the different discriminant functions (DF) were adjusted to Gaussian curves following a normal distribution and projected onto ROIs. DF is a variable that was composed to maximize the variance between the groups and to minimize the variance within the groups.

The lipids and metabolites were then identified using tandem MS as well as the databases, LIPID MAPS Structure Database (http://lipidmaps.org), ALEX123 lipid database (http://alex123.info/ALEX123/MS.php), ${ }^{31}$ METLIN database (https://metlin.scripps.edu), and Human Metabolome Database (http://www.hmdb.ca/). 
A.

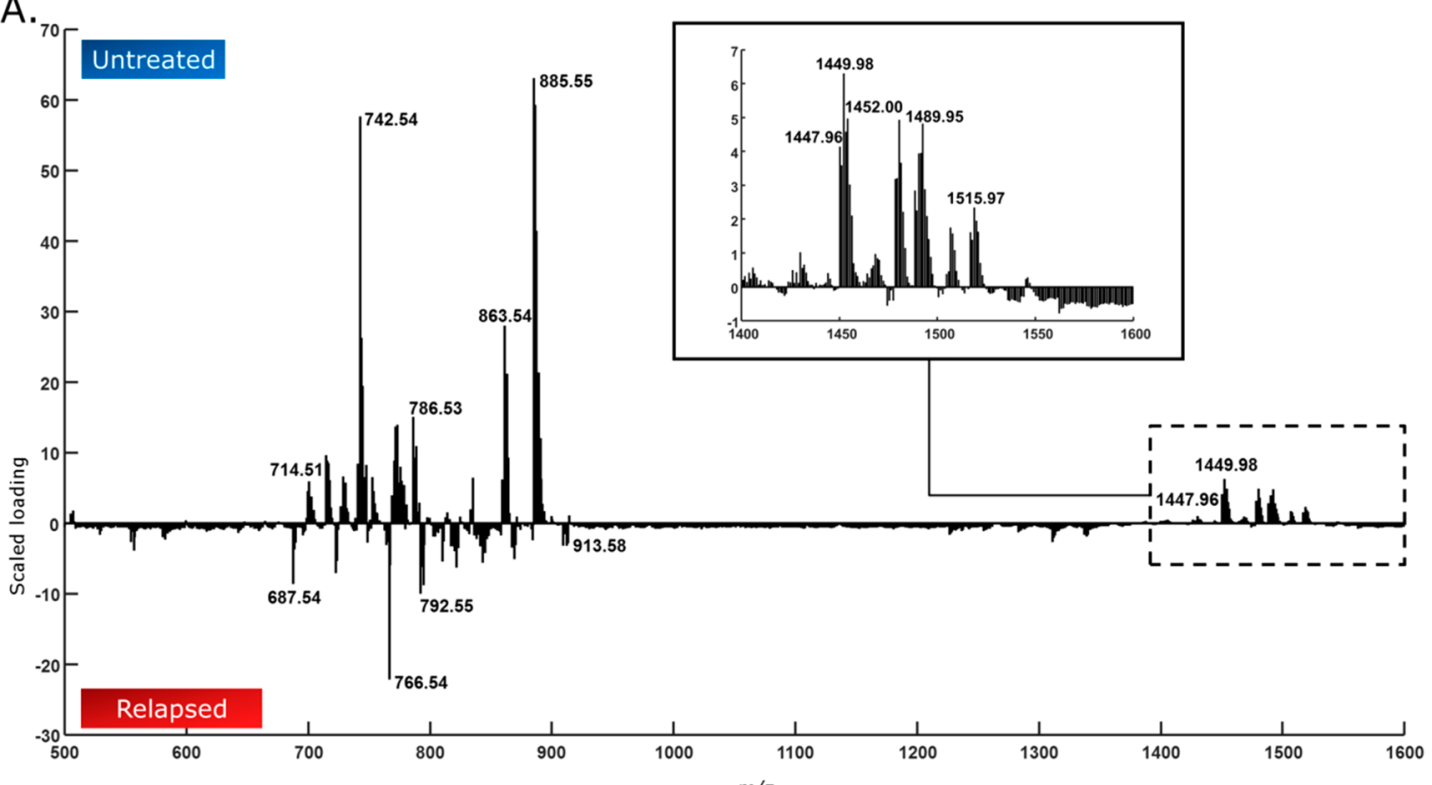

B.

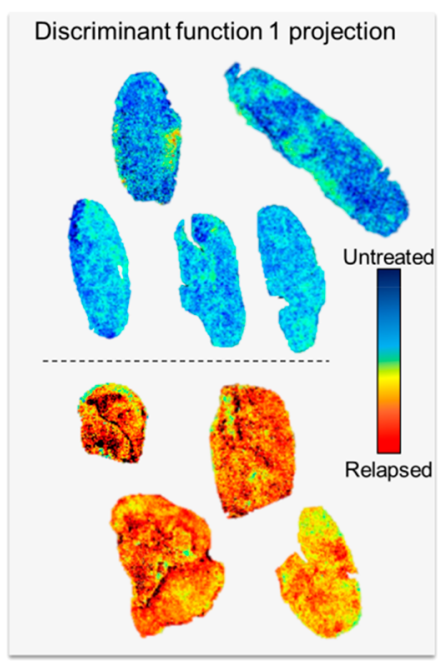

C.

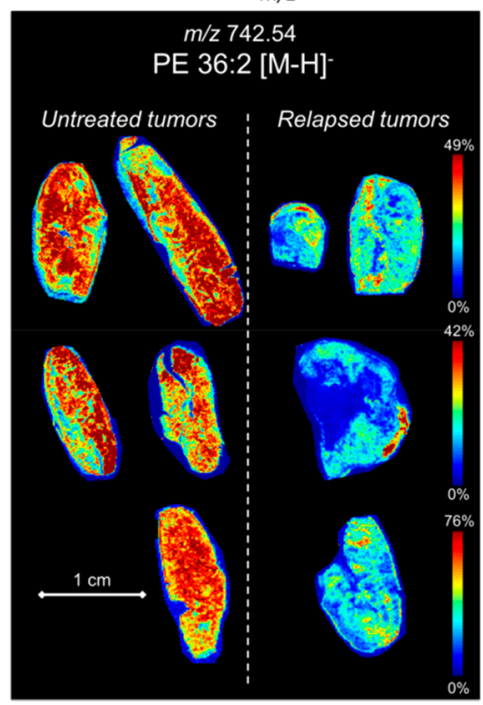

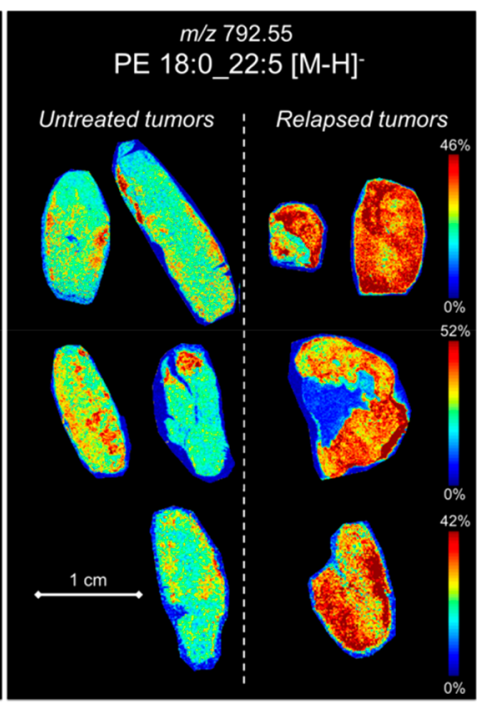

Figure 2. Discriminating untreated and R-CHOP-resistant tumors based on the lipid signature in negative polarity. (A) DF1 scaled loading spectrum. (B) DF1 score projection. (C) Single peak intensity plots of PE 36:2 $[\mathrm{M}-\mathrm{H}]^{-}$(left) and PE 18:0_22:5 $[\mathrm{M}-\mathrm{H}]^{-}$(right).

After acquisition, the tissue sections were analyzed by fluorescent microscopy and stained for histological annotation. For more details about material and methods, please see the Supporting Information.

\section{RESULTS AND DISCUSSION}

In Vivo Imaging Monitoring To Follow the Tumor Growth. We selected the U2932 DLBCL cell line to generate our in vivo model (Figure 1A), as it presents a high expression of $\mathrm{v}$-myc avian myelocytomatosis viral oncogene homologue (MYC) and B-cell lymphoma 2 (BCL2), ${ }^{32}$ a hallmark of refractory/relapse DLBCL patients. ${ }^{33}$ Using the pFULT lentiviral system, we generated a variant of this cell line stably and constitutively expressing luciferase 2 as well as TdTomato (Figure 1A). In a pilot experiment, we validated the possibility of monitoring tumor development from these xenografts and observed that tumors should reach a minimum total signal of 3 $\times 10^{10}$ photons/second before starting R-CHOP therapy in order to obtain refractory/relapsing tumors (data not shown). Then, we injected 40 mice, leading to 33 animals developing tumors without presenting side-effects; 5 control mice were not treated (Figure 1B), presenting constant tumor growth (Figures $1 \mathrm{C}$ and $\mathrm{S} 1$ ); and 28 were treated with the R-CHOP regimen. As our aim was to characterize $\mathrm{R}-\mathrm{CHOP}$ resistance, we defined resistant tumors as those presenting regular tumor growth after serial regimens of R-CHOP treatment (Figure 1D). Under this criterion, 4 of the 28 injected, treated mice showed R-CHOP-resistant tumors (Figures 1D and S1).

Differential Lipid Profiles between Untreated and Relapsing Tumors Revealed by MALDI-MSI. Different lipid profiles between untreated and R-CHOP-resistant tumors were revealed by MALDI-MSI $(100 \times 100 \mu \mathrm{m}$ raster size $)$. Both ion polarities allowed for the visualization of different molecular classes. In negative-ion mode (Figure 2, Table 1), we detected phosphatidylinositols (PI), phosphatidylethanolamines (PE), phosphatidylserines (PS), phosphatidylglycerols (PG), and cardiolipins (CL). Principal component analysis followed by linear discriminant analysis (PCA-LDA) was used for data reduction and to look for specific profiles of each condition (Figure 2A). 
Table 1. Lipid Assignments Based on MS/MS and High Mass Resolution MSI Experiments

\begin{tabular}{|c|c|c|c|c|}
\hline $\mathrm{m} / \mathrm{z}$ value & Assignment & Designation & Condition DF1 & PPM error \\
\hline 524.37 & LPC 18:0 & {$[\mathrm{M}+\mathrm{H}]^{+}$} & Relapsed & 0.39 \\
\hline 725.56 & $\operatorname{SM}(34: 1 ; 2)$ & {$[\mathrm{M}+\mathrm{Na}]^{+}$} & Relapsed & 0.28 \\
\hline 756.55 & PC 32:0 (16:0/16:0) & {$[\mathrm{M}+\mathrm{Na}]^{+}$} & Relapsed & 0.50 \\
\hline 786.60 & PC $36: 2$ & {$[\mathrm{M}+\mathrm{H}]^{+}$} & Untreated & 1.00 \\
\hline 796.53 & PC $34: 2$ & {$[\mathrm{M}+\mathrm{K}]^{+}$} & Untreated & 0.66 \\
\hline 808.58 & PC 36:2 & {$[\mathrm{M}+\mathrm{Na}]^{+}$} & Relapsed & 0.87 \\
\hline 832.58 & PC 38:4 & {$[\mathrm{M}+\mathrm{Na}]^{+}$} & Relapsed & 0.65 \\
\hline 834.58 & PC O_38:4 & {$[\mathrm{M}+\mathrm{K}]^{+}$} & Relapsed & 1.17 \\
\hline 687.54 & $\begin{array}{l}\text { [M-CH3] Fragment from } m / z \text { SM } \\
\text { d18:1_16:0 }\end{array}$ & {$[\mathrm{M}-\mathrm{H}]^{-}$} & Relapsed & 0.52 \\
\hline 689.56 & $\begin{array}{c}{\left[\mathrm{M}_{-} \mathrm{CH} 3\right]^{-} \text {Fragment from } \mathrm{m} / \mathrm{z} \mathrm{SM}} \\
\text { d18:0_16:0 }\end{array}$ & {$[\mathrm{M}-\mathrm{H}]^{-}$} & Relapsed & 1.29 \\
\hline 714.51 & PE 16:0_18:2 & {$[\mathrm{M}-\mathrm{H}]^{-}$} & Untreated & -0.31 \\
\hline 738.51 & PE 16:0_20:4 & {$[\mathrm{M}-\mathrm{H}]^{-}$} & Untreated & -0.03 \\
\hline 740.52 & PE $36: 3$ & {$[\mathrm{M}-\mathrm{H}]^{-}$} & Untreated & -0.31 \\
\hline 742.54 & PE 36:2 & {$[\mathrm{M}-\mathrm{H}]^{-}$} & Untreated & -0.03 \\
\hline 747.52 & PG 16:0_18:1 & {$[\mathrm{M}-\mathrm{H}]^{-}$} & Untreated & -0.56 \\
\hline 766.54 & PE 18:0_20:4 & {$[\mathrm{M}-\mathrm{H}]^{-}$} & Relapsed & -0.70 \\
\hline 770.57 & DMPE 36:2 & {$[\mathrm{M}-\mathrm{H}]^{-}$} & Untreated & -0.04 \\
\hline 773.53 & PG 36:2 & {$[\mathrm{M}-\mathrm{H}]^{-}$} & Untreated & -0.36 \\
\hline 786.53 & PS 18:0_18:2 & {$[\mathrm{M}-\mathrm{H}]^{-}$} & Untreated & -0.21 \\
\hline 792.55 & PE 18:0_22:5 & {$[\mathrm{M}-\mathrm{H}]^{-}$} & Relapsed & -1.00 \\
\hline 821.53 & PG 18:1_22:5 & {$[\mathrm{M}-\mathrm{H}]^{-}$} & Relapsed & -1.14 \\
\hline 823.55 & PG $4 \overline{0}: 5$ & {$[\mathrm{M}-\mathrm{H}]^{-}$} & Relapsed & -0.70 \\
\hline 838.56 & PS 18:0_22:4 & {$[\mathrm{M}-\mathrm{H}]^{-}$} & Relapsed & -0.53 \\
\hline 843.52 & PG 20:4_22:5 & {$[\mathrm{M}-\mathrm{H}]^{-}$} & Relapsed & -0.89 \\
\hline 857.52 & PI 16:0_20:4 & {$[\mathrm{M}-\mathrm{H}]^{-}$} & Relapsed & -1.27 \\
\hline 885.55 & PI 18:0_20:4 & {$[\mathrm{M}-\mathrm{H}]^{-}$} & Untreated & -1.07 \\
\hline 909.55 & PI 18:0_22:6 & {$[\mathrm{M}-\mathrm{H}]^{-}$} & Relapsed & -1.17 \\
\hline 913.58 & PI 18:0_22:4 & {$[\mathrm{M}-\mathrm{H}]^{-}$} & Relapsed & -1.19 \\
\hline 1447.96 & $\mathrm{CL}(18: 2) 4$ & {$[\mathrm{M}-\mathrm{H}]^{-}$} & Untreated & -0.97 \\
\hline 1449.98 & CL (18:1)1_(18:2)3 & {$[\mathrm{M}-\mathrm{H}]^{-}$} & Untreated & -0.91 \\
\hline 1452.00 & CL $(18: 1) 2 \_(18: 2) 2$ & {$[\mathrm{M}-\mathrm{H}]^{-}$} & Untreated & -0.45 \\
\hline 1473.98 & $C L(18: 1) 2 \_(18: 2) 2$ & {$[\mathrm{M}+\mathrm{Na}-2 \mathrm{H}]^{-}$} & Relapsed & -0.44 \\
\hline 1478.01 & $\mathrm{CL} 72: 4$ & {$[\mathrm{M}+\mathrm{Na}-2 \mathrm{H}]^{-}$} & Untreated & -0.86 \\
\hline 1485.92 & $\mathrm{CL}(18: 2) 4$ & {$[\mathrm{M}+\mathrm{K}-2 \mathrm{H}]^{-}$} & Untreated & -0.62 \\
\hline 1487.94 & CL (18:1)1_(18:2)3 & {$[\mathrm{M}+\mathrm{K}-2 \mathrm{H}]^{-}$} & Untreated & 0 \\
\hline 1489.95 & $C L(18: 1) 2 \_(18: 2) 2$ & {$[\mathrm{M}+\mathrm{K}-2 \mathrm{H}]^{-}$} & Untreated & -0.13 \\
\hline 1513.95 & CL (18:2)3_(20:2)1 & {$[\mathrm{M}+\mathrm{K}-2 \mathrm{H}]^{-}$} & Untreated & -0.4 \\
\hline 1515.97 & CL (18:1)1_(18:2)2_(20:2)1 & {$[\mathrm{M}+\mathrm{K}-2 \mathrm{H}]^{-}$} & Untreated & -0.24 \\
\hline
\end{tabular}

The DF 1 of lipids in negative mode described $1.5 \%$ of the total variance used for the LDA. The projection of the DF1 scores revealed different biomolecular profiles for the untreated and resistant tumors (Figure 2B). Of importance, different lipid families appeared to be specific to each condition (Table 1). PI and most PG species were specific of R-CHOP-resistant tumors, whereas most $\mathrm{PE}$ and $\mathrm{CL}$ species were predominantly detected in the untreated condition (Figure 2A,C). The higher presence of PI in the relapsed condition is biologically relevant as phosphoinositide 3-kinase, a key cellular signaling mediator of this lipid family, which has been shown to be involved in DLBCL pathogenesis by having a role in protein trafficking ${ }^{34}$ and is currently being investigated as a target for refractory/ relapsed DLBCL. ${ }^{35}$ Of note, we also observed some lipid fragments from sphingomyelins (SM) d18:1_16:0 ( $\mathrm{m} / \mathrm{z}$ 687.54, $\left.[\mathrm{M}-\mathrm{H}]^{-}\right)$, exclusively localized in certain tumor regions.

In the positive-ion mode, different lipid classes, such as phosphocholines (PC), SM, and PE, were detected (Table 1). The DF1 was discriminated between the two conditions (Figure 3A,B), describing $1.1 \%$ of the total variance used for the LDA. Likewise, individual lipids were more abundant in one condition compared to the other (Table 1). For instance, PC 34:2 $\left(m / z 796.53,[\mathrm{M}+\mathrm{K}]^{+}\right)$was specific to the untreated DLBCL, whereas PC O_38:4 $\left(\mathrm{m} / z\right.$ 834.58, $\left.[\mathrm{M}+\mathrm{K}]^{+}\right)$was more present in the resistant tumors (Figure 3A,C). Most of the sodiated lipid adducts were detected in the resistant condition. An interesting case is PC $36: 2$, predominantly detected as $m / z 786.60[\mathrm{M}+\mathrm{H}]^{+}$in untreated tumors and as $m / z$ 808.58 $[\mathrm{M}+\mathrm{Na}]^{+}$in the resistant condition (Table 1). Other examples are SM $(34: 1: 2)\left(m / z\right.$ 725.56, $\left.[\mathrm{M}+\mathrm{Na}]^{+}\right)$ (Figure S3) and PC 38:4 $\left(\mathrm{m} / z\right.$ 832.58, $\left.[\mathrm{M}+\mathrm{Na}]^{+}\right)$, found to be more present in the relapsed tumors. These observations suggest that a higher content of $\mathrm{Na}^{+}$would be involved in $\mathrm{R}$ CHOP resistance mechanisms. Chughtai et al. ${ }^{36}$ found that the SM d18:1/16:0 sodium adduct primarily colocalized with hypoxic and necrotic tumor regions, agreeing with Irigoyen et al. ${ }^{37}$ who showed a correlation between hypoxia with the aggressiveness, metastatic spread, and relapse of solid tumors.

Tumor Heterogeneity Characterized by MSI Lipidomic Profiles. Fluorescence microscopy experiments confirmed that all tumoral cells expressed TdTomato protein, which was introduced in our DLBCL human cell line model (Figures 1 and S2). This excluded the possibility of having resected murine tissue with the tumor. Second, the H\&E stained slides were annotated by a pathologist, and we identified these areas as necrotic regions (Figure S4A). MSI of the treatment-resistant tumors (tumors 272 and 285) distinguished between viable and necrotic regions, which were similar to pathologist annotations in H\&E-stained slides (Figure S4). PCA was performed to evaluate specific lipid profiles linked to these different tumor areas (Figure S4B,C). In order to further study tumor heterogeneity and identify characteristic lipids of each area, we performed experiments at a higher spatial $(30 \mu \mathrm{m})$ and mass resolution (240000 resolving power at $m / z 400)$. In Figure 4, individual channels were plotted to represent the specific lipid distribution in viable and necrotic parts of resistant tumors. In the negative mode, we were able to discriminate viable/necrotic areas, with a higher presence of PI 18:0_20:4 $\left(m / z\right.$ 885.55, $\left.[\mathrm{M}-\mathrm{H}]^{-}\right)$in the viable regions, while the SM d18:1_16:0 fragment $(\mathrm{m} / z$ 687.54, $[\mathrm{M}-\mathrm{H}]^{-}$) was a marker for the $\bar{d}$ ead cell state (Figure $4 \mathrm{~A})$. In the positive mode, we observed that PC $34: 2(\mathrm{~m} / \mathrm{z}$ 796.53, $\left.[\mathrm{M}+\mathrm{K}]^{+}\right)$was a marker of the viable but R-CHOPresistant tumor tissue, whereas LPC 18:0 $(\mathrm{m} / z$ 524.37, $[\mathrm{M}+$ $\mathrm{H}]^{+}$) was specific to the necrotic part (Figure 4B). This finding confirms previous studies that detected high PC levels in nonnecrotic tumor regions, revealing importance of PCs in the following the tumor progression. ${ }^{38}$ In fact, Glunde et al. described the importance of targeting choline metabolites for early cancer detection. ${ }^{39}$

As mentioned above, most of the sodiated adducts were assigned to the resistant condition. In addition, the distribution of these sodiated species seemed to be specific to the necrotic areas of resistant tumors; SM (34:1:2) $(\mathrm{m} / z$ 725.56, $[\mathrm{M}+$ $\mathrm{Na}]^{+}$) (Figure S3), PC 36:2 $\left(\mathrm{m} / z\right.$ 808.58, $\left.[\mathrm{M}+\mathrm{Na}]^{+}\right), \mathrm{PC}$ 32:0 $(16: 0 / 16: 0)\left(\mathrm{m} / z\right.$ 756.55, $\left.[\mathrm{M}+\mathrm{Na}]^{+}\right)$, and PC 38:4 (m/ $z$ 832.58, $\left.[\mathrm{M}+\mathrm{Na}]^{+}\right)$are several examples. Our observations are in agreement with those of Amstalden van Hove et al., who also observed higher levels of $\mathrm{Na}^{+}$in the necrotic tumor regions by $\mathrm{MSI}^{38}$ It is possible, that high $\mathrm{Na}^{+}$levels lead to necrosis, or that this high sodium presence could be a consequence of the cell death process. These high sodium levels may also correlate with a decrease in $\mathrm{Na}^{+} / \mathrm{K}^{+}$pump activity and an increase in cell permeability. ${ }^{34,36}$ Interestingly, higher potassiated lipid species were found in viable compared to necrotic tissue, such as PC $34: 2\left(m / z 796.53,[\mathrm{M}+\mathrm{K}]^{+}\right)$. This is supported as well by Summers et al., who showed that 
A.

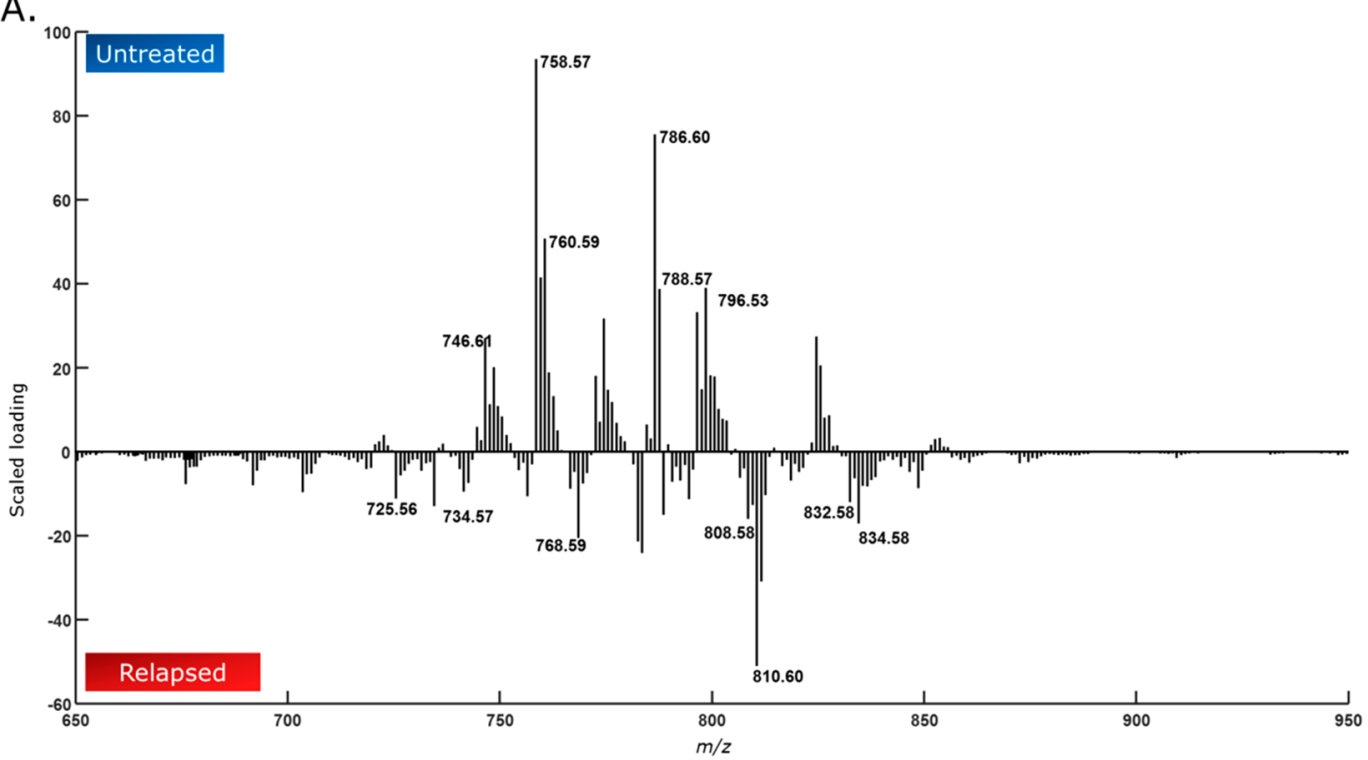

B.

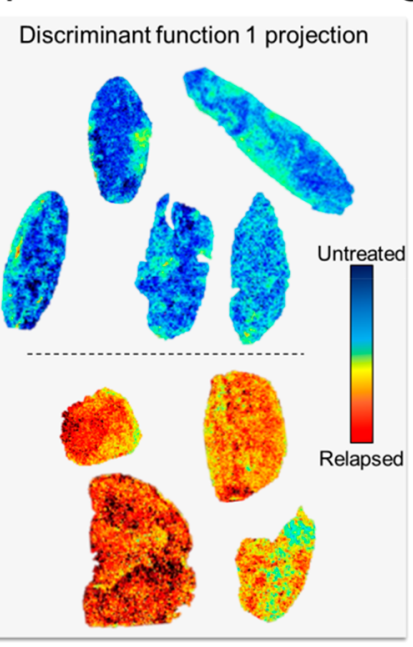

C.

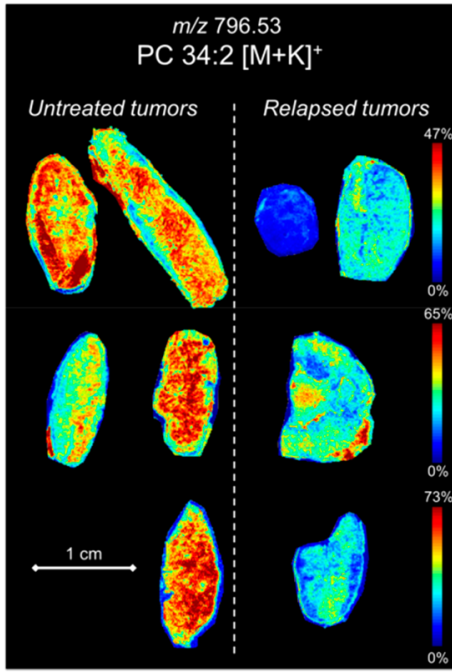

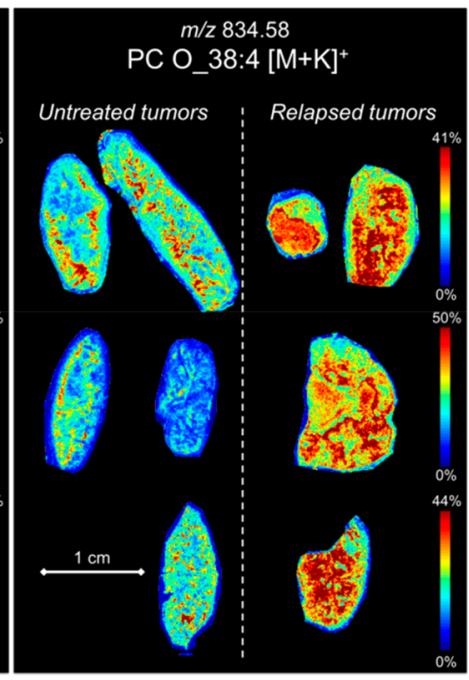

Figure 3. Discriminating untreated and R-CHOP-resistant tumors based on the lipid signature in positive polarity. (A) DF1 scaled loading spectrum. (B) DF1 score projection. (C) Single peak intensity plots of PC 34:2 [M + K $]^{+}$(left) and PC O_38:4 $[\mathrm{M}+\mathrm{K}]^{+}$(right).

higher $\mathrm{K}^{+}$levels were found in viable tumor regions compared to necrotic areas. ${ }^{40}$ Our results suggest that the presence of sodiated lipids could indicate a good response to R-CHOP therapy.

Metabolic Changes in Relapsed DLBCL Tumors. After we optimized our method for MALDI-MSI detection of small molecules using 9-AA and NEDC, ${ }^{41,42}$ we observed a higher signal-to-noise ratio for metabolites, such as adenosine monophosphate (AMP, $m / z$ 346.06), adenosine diphosphate (ADP, $m / z$ 426.02), and adenosine triphosphate (ATP, $m / z$ 505.99), using NEDC. In addition, the matrix peaks were less abundant in the mass spectrum with NEDC compared to 9AA, which helped to avoid matrix interferences (Figure S5). NEDC allowed the analysis of lipids and metabolites in a single experiment. Hence, we performed analysis targeting metabolites using NEDC at a raster size of $100 \mu \mathrm{m}$.

PCA-LDA showed a separation between the untreated and resistant tumors (Figure 5A). The DF1 described $2.0 \%$ of the total variance used for the LDA. The DF1 score projections looked similar for all triplicates and molecular classes (Figure S6). In addition, we identified metabolites that discriminated untreated from R-CHOP resistant tumors (Figure 5B). As an example, ATP was more abundant in the untreated sections (Figure 5C), whereas AMP presented a relatively higher intensity in the viable areas of the R-CHOP-resistant tumors (Figure S7). Previous studies reported that ATP consumption serves to increase glucose flux to satisfy the energetic and biosynthetic demands of a rapidly proliferating cancer cell. ${ }^{43}$ ATP production is associated with CLs via the electron transport chain, which is involved in oxidative phosphorylation, ${ }^{42,43}$ a more efficient pathway for ATP production than glycolysis. ${ }^{44}$ We found that most of the CL species were more abundant in the untreated samples, as shown in the DF spectrum of the lipids in negative mode (Figure 2A). CLs are a class of mitochondrion-specific anionic phospholipids and play multiple structural and functional roles in bioenergetics. According to Kiebish et al., environmental factors, including necrosis and hypoxia, could alter CL content and/or composition, which could affect tumor initiation or progression. $^{45}$ Importantly, CHOP has been suggested to influence metabolism and the mitochondrial state in lymphoma xenografts in vivo. ${ }^{46,47}$ Indeed, differences in 

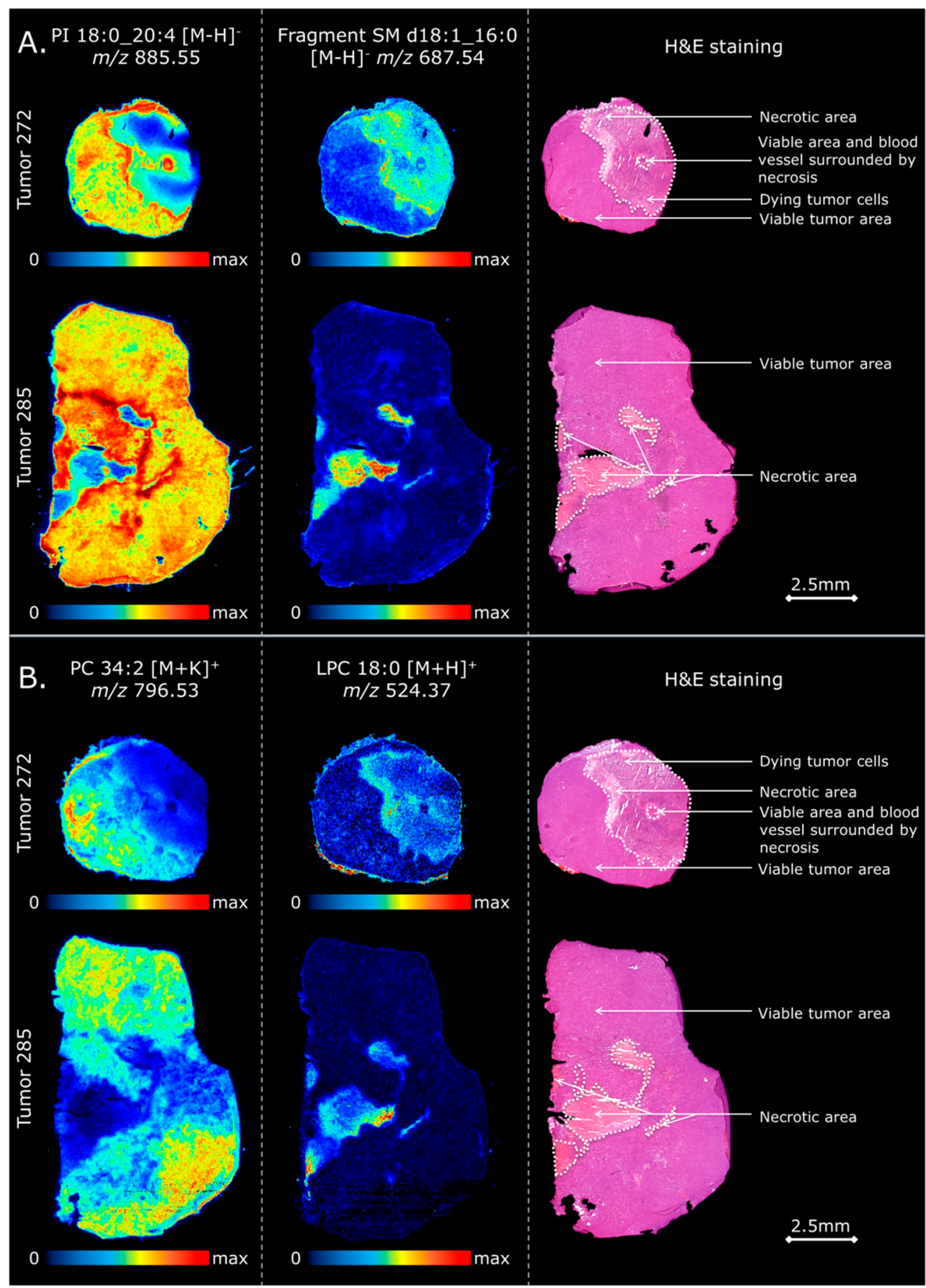

Figure 4. Intratumor heterogeneity. (A) Negative-ion mode images show the spatial distribution of PI 18:0_20:4 (left) and SM d18:1_16:0 (middle) in viable and necrotic regions, respectively, determined by H\&E staining (right). (B) Positive-ion mode images show the spatial distribution of PC 34:2 (left) and LPC 18:0 (middle), which correlated to viable and necrotic areas, respectively, again determined by H\&E staining (right).

metabolism and mitochondrial state have been characterized in lymphoma patients. ${ }^{38,39}$

Regarding glycerophosphocholine, we observed that this major form of choline storage (shown as dysregulated in cancer metabolism ${ }^{38,48,49}$ by others) was specific to resistant tumors. Interestingly, glycerophosphocholine has been associated with poor prognosis in breast cancer. ${ }^{50}$ Our findings suggest that the highest level of glycerophosphocholine present in the resistant tumors could be linked to PCs, which were also more abundant in the resistant tissues. Other groups have described a relationship between differential biomolecular profiles and cell density, which might be related to a higher cell division rate in aggressive tumors. ${ }^{51,52}$

\section{CONCLUSION}

Our approach shows the potential of combining in vivo imaging and MSI to investigate molecular differences associated with successful and nonresponsive cancer treatment. To our knowledge, our study is the first that combines bioluminescence in vivo imaging, for characterization of lipids 


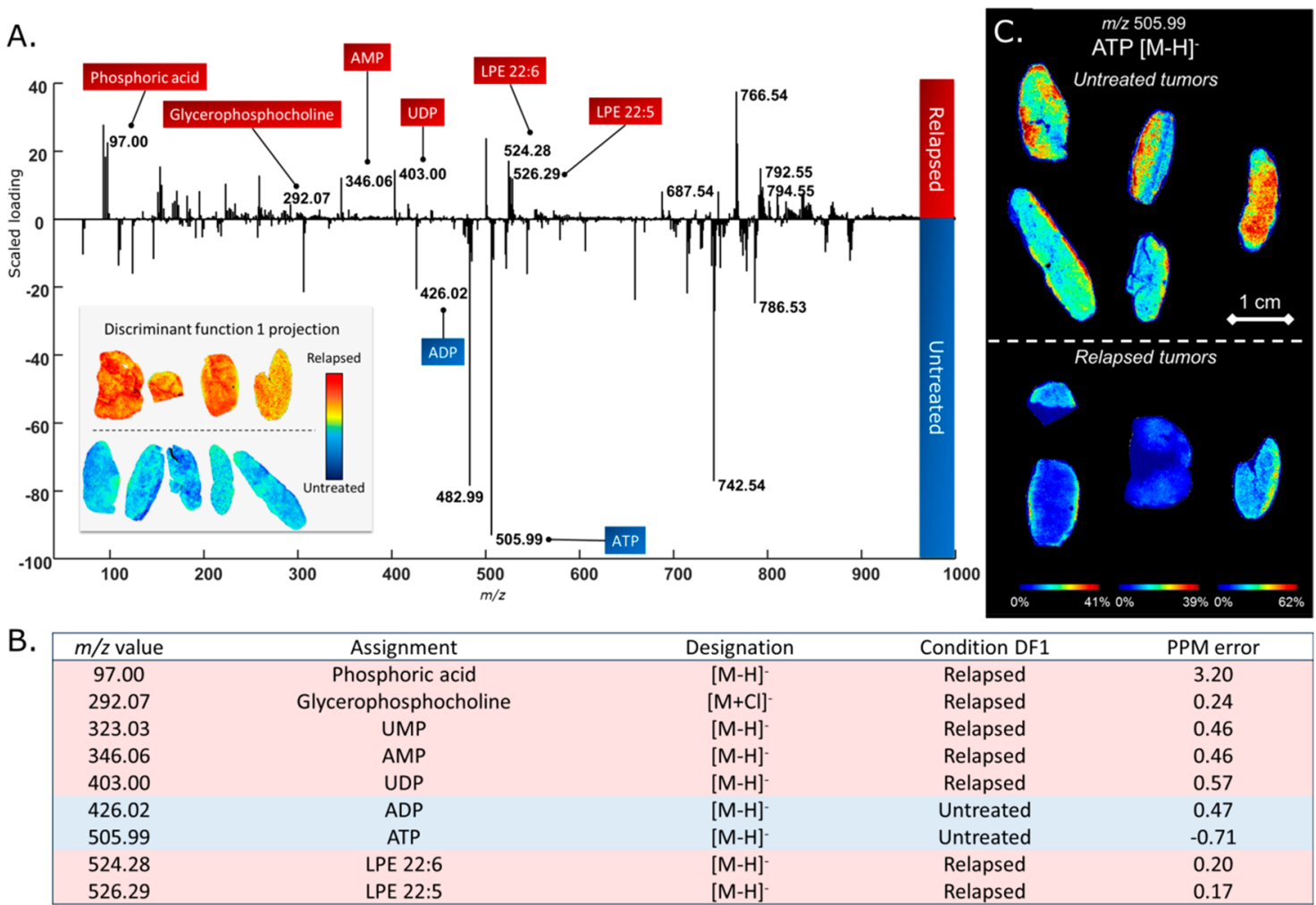

Figure 5. Metabolic classification of nontreated and R-CHOP-resistant tumors. (A) DF1 scaled loading spectrum. (B) Metabolite assignments. (C) Single peak intensity plots showing a relative predominance of ATP in untreated tumors.

and metabolic profiles associated with R-CHOP resistant tumors. Moreover, specific molecular signatures could be associated with intratumor heterogeneity. MSI is a robust tool to discover new markers and signatures of lymphoma, which could be applied to investigate other cancers and their specific treatment success/resistance.

\section{ASSOCIATED CONTENT}

\section{S Supporting Information}

The Supporting Information is available free of charge on the ACS Publications website at DOI: 10.1021/acs.analchem.8b02910.

Materials and methods, MALDI-MSI, representative IVIS acquisitions, presence of TdTomato fluorescent protein, single intensity plot, intratumor heterogeneity, matrix optimization, discriminant function projections, and tumor heterogeneity (PDF)

\section{AUTHOR INFORMATION}

\section{Corresponding Author}

*Tel.: +31 $43 \quad 388 \quad 4 \quad 839$; E-mail: b.cilleropastor@ maastrichtuniversity.nl.

\section{ORCID}

Ron M.A. Heeren: 0000-0002-6533-7179

Berta Cillero-Pastor: 0000-0002-7407-1165

\section{Author Contributions}

${ }^{\#}$ F.P.Y.B. and B.S.R.C. contributed equally to this work.

\section{Author Contributions}

${ }^{\mathrm{I}}$ C.C. and B.C.P. contributed equally to this work.

\section{Notes}

The authors declare no competing financial interest.

\section{ACKNOWLEDGMENTS}

This work has been financially supported by the Dutch Province of Limburg as part of the "LINK" program and by the European Union's Horizon 2020 research and innovation program under the Marie Sklodowska-Curie grant agreement 642414. We thank Dr. Kevin Knoops (M4I, division of Nanoscopy, Maastricht University) for his help with fluorescence microscopy experiments. The in vivo experiments have been supported by the Danish Council for Independent Research (Sapere Aude program), the Novo Nordisk Foundation, the Lundbeck Foundation, and the Danish Cancer Society, and the Grønbæk laboratory was supported by the Danish Cancer Society (R132-A8315).

\section{REFERENCES}

(1) Siegel, R. L.; Miller, K. D.; Jemal, A. Ca-Cancer J. Clin. 2016, 66, $7-30$.

(2) Pfreundschuh, M.; Kuhnt, E.; Trumper, L.; Osterborg, A.; Trneny, M.; Shepherd, L.; Gill, D. S.; Walewski, J.; Pettengell, R.; Jaeger, U.; Zinzani, P. L.; Shpilberg, O.; Kvaloy, S.; de Nully Brown, P.; Stahel, R.; Milpied, N.; Lopez-Guillermo, A.; Poeschel, V.; Grass, S.; Loeffler, M.; Murawski, N. Lancet Oncol. 2011, 12, 1013-1022.

(3) Fisher, R. I.; Gaynor, E. R.; Dahlberg, S.; Oken, M. M.; Grogan, T. M.; Mize, E. M.; Glick, J. H.; Coltman, C. A., Jr.; Miller, T. P. N. Engl. J. Med. 1993, 328, 1002-1006.

(4) Coiffier, B.; Thieblemont, C.; Van Den Neste, E.; Lepeu, G.; Plantier, I.; Castaigne, S.; Lefort, S.; Marit, G.; Macro, M.; Sebban, C.; Belhadj, K.; Bordessoule, D.; Ferme, C.; Tilly, H. Blood 2010, 116, 2040-2045.

(5) Salles, G.; Barrett, M.; Foa, R.; Maurer, J.; O’Brien, S.; Valente, N.; Wenger, M.; Maloney, D. G. Adv. Ther. 2017, 34, 2232-2273.

(6) Roschewski, M.; Staudt, L. M.; Wilson, W. H. Nat. Rev. Clin. Oncol. 2014, 11, 12-23. 
(7) Blay, J.; Gomez, F.; Sebban, C.; Bachelot, T.; Biron, P.; Guglielmi, C.; Hagenbeek, A.; Somers, R.; Chauvin, F.; Philip, T. Blood 1998, 92, 3562-3568.

(8) Martelli, M.; Ferreri, A. J.; Agostinelli, C.; Di Rocco, A.; Pfreundschuh, M.; Pileri, S. A. Critical reviews in oncology/hematology 2013, 87, 146-171.

(9) Contag, C. H.; Spilman, S. D.; Contag, P. R.; Oshiro, M.; Eames, B.; Dennery, P.; Stevenson, D. K.; Benaron, D. A. Photochem. Photobiol. 1997, 66, 523-531.

(10) Sweeney, T. J.; Mailander, V.; Tucker, A. A.; Olomu, A. B.; Zhang, W.; Cao, Y.; Negrin, R. S.; Contag, C. H. Proc. Natl. Acad. Sci. U. S. A. 1999, 96, 12044-12049.

(11) Liu, H.; Patel, M. R.; Prescher, J. A.; Patsialou, A.; Qian, D.; Lin, J.; Wen, S.; Chang, Y. F.; Bachmann, M. H.; Shimono, Y.; Dalerba, P.; Adorno, M.; Lobo, N.; Bueno, J.; Dirbas, F. M.; Goswami, S.; Somlo, G.; Condeelis, J.; Contag, C. H.; Gambhir, S. S.; Clarke, M. F. Proc. Natl. Acad. Sci. U. S. A. 2010, 107, 18115-18120.

(12) Robertson, R.; Germanos, M. S.; Manfredi, M. G.; Smith, P. G.; Silva, M. D. J. Nucl. Med. 2011, 52, 1764-1769.

(13) Caprioli, R. M.; Farmer, T. B.; Gile, J. Anal. Chem. 1997, 69, $4751-4760$

(14) Ellis, S. R.; Cappell, J.; Potocnik, N. O.; Balluff, B.; Hamaide, J.; Van der Linden, A.; Heeren, R. M. A. Analyst 2016, 141, 3832-3841.

(15) Dilillo, M.; Ait-Belkacem, R.; Esteve, C.; Pellegrini, D.; Nicolardi, S.; Costa, M.; Vannini, E.; Graaf, E. L.; Caleo, M.; McDonnell, L. A. Sci. Rep. 2017, 7, 603.

(16) Barre, F. P.; Flinders, B.; Garcia, J. P.; Jansen, I.; Huizing, L. R.;

Porta, T.; Creemers, L. B.; Heeren, R. M.; Cillero-Pastor, B. Anal. Chem. 2016, 88, 12051-12059.

(17) Sans, M.; Gharpure, K.; Tibshirani, R.; Zhang, J.; Liang, L.; Liu, J.; Young, J. H.; Dood, R. L.; Sood, A. K.; Eberlin, L. S. Cancer Res. 2017, 77, 2903-2913.

(18) Delcourt, V.; Franck, J.; Leblanc, E.; Narducci, F.; Robin, Y. M.; Gimeno, J. P.; Quanico, J.; Wisztorski, M.; Kobeissy, F.; Jacques, J. F.; Roucou, X.; Salzet, M.; Fournier, I. EBioMedicine 2017, 21, 55-64.

(19) Caprioli, R. M.; Farmer, T. B.; Zhang, H. Y.; Stoeckli, M. Abstr Pap Am. Chem. S 1997, 214, 113-ANYL.

(20) Feenstra, A. D.; Duenas, M. E.; Lee, Y. J. J. Am. Soc. Mass Spectrom. 2017, 28, 434-442.

(21) Zavalin, A.; Yang, J.; Hayden, K.; Vestal, M.; Caprioli, R. M. Anal. Bioanal. Chem. 2015, 407, 2337-2342.

(22) Prentice, B. M.; Chumbley, C. W.; Caprioli, R. M. J. Mass Spectrom. 2015, 50, 703-710.

(23) Hinsenkamp, I.; Schulz, S.; Roscher, M.; Suhr, A. M.; Meyer, B.; Munteanu, B.; Fuchser, J.; Schoenberg, S. O.; Ebert, M. P. A.; Wangler, B.; Hopf, C.; Burgermeister, E. Neoplasia 2016, 18, 500511.

(24) Jiang, W. G.; Davies, G.; Martin, T. A.; Parr, C.; Watkins, G.; Mansel, R. E.; Mason, M. D. Int. J. Mol. Med. 2006, 16, 723-728.

(25) Damas, N. D.; Marcatti, M.; Come, C.; Christensen, L. L.; Nielsen, M. M.; Baumgartner, R.; Gylling, H. M.; Maglieri, G.; Rundsten, C. F.; Seemann, S. E.; Rapin, N.; Thezenas, S.; Vang, S.; Orntoft, T.; Andersen, C. L.; Pedersen, J. S.; Lund, A. H. Nat. Commun. 2016, 7, 13875.

(26) Ansell, S. M.; Arendt, B. K.; Grote, D. M.; Jelinek, D. F.; Novak, A. J.; Wellik, L. E.; Remstein, E. D.; Bennett, C. F.; Fielding, A. Leukemia 2004, 18, 616-623.

(27) Mori, F.; Ishida, T.; Ito, A.; Sato, F.; Masaki, A.; Takino, H.; Ri, M.; Kusumoto, S.; Komatsu, H.; Ueda, R.; Inagaki, H.; Iida, S. Blood Cancer Journal 2012, 2, e67.

(28) Bakker, B.; Eijkel, G. B.; Heeren, R. M. A.; Karperien, M.; Post, J. N.; Cillero-Pastor, B. Anal. Chem. 2017, 89, 9438-9444.

(29) Eijkel, G. B.; Kaletas, B. K.; van der Wiel, I. M.; Kros, J. M.; Luider, T. M.; Heeren, R. M. A. Surf. Interface Anal. 2009, 41, 675685.

(30) Hoogerbrugge, R.; Willig, S. J.; Kistemaker, P. G. Anal. Chem. $1983,55,1710-1712$.
(31) Ellis, S. R.; Paine, M. R. L.; Eijkel, G. B.; Pauling, J. K.; Husen, P.; Jervelund, M. W.; Hermansson, M.; Ejsing, C. S.; Heeren, R. M. A. Nat. Methods 2018, 15, 515.

(32) Mahadevan, D.; Morales, C.; Cooke, L. S.; Manziello, A.; Mount, D. W.; Persky, D. O.; Fisher, R. I.; Miller, T. P.; Qi, W. PLoS One 2014, 9, No. e95184.

(33) Coiffier, B.; Sarkozy, C. Hematology/the Education Program of the American Society of Hematology. American Society of Hematology. Education Program 2016, 2016, 366-378.

(34) Uddin, S.; Hussain, A. R.; Siraj, A. K.; Manogaran, P. S.; AlJomah, N. A.; Moorji, A.; Atizado, V.; Al-Dayel, F.; Belgaumi, A.; ElSolh, H.; Ezzat, A.; Bavi, P.; Al-Kuraya, K. S. Blood 2006, 108, 41784186.

(35) Dreyling, M.; Santoro, A.; Mollica, L.; Leppa, S.; Follows, G. A.; Lenz, G.; Kim, W. S.; Nagler, A.; Panayiotidis, P.; Demeter, J.; Ozcan, M.; Kosinova, M.; Bouabdallah, K.; Morschhauser, F.; Stevens, D. A.; Trevarthen, D.; Giurescu, M.; Cupit, L.; Liu, L.; Kochert, K.; Seidel, H.; Pena, C.; Yin, S.; Hiemeyer, F.; Garcia-Vargas, J.; Childs, B. H.; Zinzani, P. L. J. Clin. Oncol. 2017, 35, 3898-3905.

(36) Chughtai, K.; Jiang, L.; Greenwood, T. R.; Glunde, K.; Heeren, R. M. A. J. Lipid Res. 2013, 54, 333-344.

(37) Irigoyen, M.; García-Ruiz, J. C.; Berra, E. Oncotarget 2017, 8, 36832-36844.

(38) Amstalden van Hove, E. R.; Blackwell, T. R.; Klinkert, I.; Eijkel, G. B.; Heeren, R. M.; Glunde, K. Cancer Res. 2010, 70, 9012-9021.

(39) Glunde, K.; Jacobs, M. A.; Bhujwalla, Z. M. Expert Rev. Mol. Diagn. 2006, 6, 821-829.

(40) Summers, R. M.; Joseph, P. M.; Kundel, H. L. Invest. Radiol. 1991, 26, 233-241.

(41) Wang, J.; Qiu, S.; Chen, S.; Xiong, C.; Liu, H.; Wang, J.; Zhang, N.; Hou, J.; He, Q.; Nie, Z. Anal. Chem. 2015, 87, 422-430.

(42) Ly, A.; Buck, A.; Balluff, B.; Sun, N.; Gorzolka, K.; Feuchtinger, A.; Janssen, K. P.; Kuppen, P. J.; van de Velde, C. J.; Weirich, G.; Erlmeier, F.; Langer, R.; Aubele, M.; Zitzelsberger, H.; McDonnell, L.; Aichler, M.; Walch, A. Nat. Protoc. 2016, 11, 1428-1443.

(43) Fang, M.; Shen, Z. R.; Huang, S.; Zhao, L. P.; Chen, S.; Mak, T. W.; Wang, X. D. Cell 2010, 143, 711-724.

(44) Zheng, J. Oncol. Lett. 2012, 4, 1151-1157.

(45) Kiebish, M. A.; Han, X.; Cheng, H.; Chuang, J. H.; Seyfried, T. N. J. Lipid Res. 2008, 49, 2545-2556.

(46) Xu, H. N.; Mir, T. A.; Lee, S. C.; Feng, M.; Farhad, N.; Choe, R.; Glickson, J. D.; Li, L. Z. Adv. Exp. Med. Biol. 2013, 789, 243-249.

(47) Xu, H. N.; Zhao, H.; Mir, T. A.; Lee, S. C.; Feng, M.; Choe, R.; Glickson, J. D.; Li, L. Z. J. Innovative Opt. Health Sci. 2013, 06, 1350011.

(48) Xiong, J.; Bian, J.; Wang, L.; Zhou, J. Y.; Wang, Y.; Zhao, Y.; Wu, L. L.; Hu, J. J.; Li, B.; Chen, S. J.; Yan, C.; Zhao, W. L. Blood Cancer J. 2015, 5, e287.

(49) Glunde, K.; Penet, M. F.; Jiang, L.; Jacobs, M. A.; Bhujwalla, Z. M. Expert Rev. Mol. Diagn. 2015, 15, 735-747.

(50) Moestue, S. A.; Giskeodegard, G. F.; Cao, M. D.; Bathen, T. F.; Gribbestad, I. S. Proc. Natl. Acad. Sci. U. S. A. 2012, 109, E2506.

(51) Hamm, G.; Bonnel, D.; Legouffe, R.; Pamelard, F.; Delbos, J. M.; Bouzom, F.; Stauber, J. J. Proteomics 2012, 75, 4952-4961.

(52) Taylor, A. J.; Dexter, A.; Bunch, J. Anal. Chem. 2018, 90, 56375645 . 